\section{Modern Strategy For New Medicine Research: Study of Pharmacological Activities of Riachin, A Non-Cyanogenic Cyanoglucoside Extracted From Bauhinia Pentandra REVIEW}

\section{Introduction}

Over the years the search for new molecules is growing, the success of new discoveries often occurs with molecules arising from the nature that subsequently pass through chemical improvements. Unfortunately many of the identified and isolated substances do not reach on to become a drug, a few times a discontinuity of research or possibly the lack of interest of researchers in some structures.

Knowing that the Brazilian Flora is very diverse and still has a great variety of species not studied, each year new substances from nature are identified, many of these, possibly with the potential to become a new drug. In Northeast Brazil is not different and among the numerous plant species studied are those that make up the genus Bauhinia that has aroused the interest of researchers, among the most popular is the Bauhinia forficata. This has been used by people for many years, especially for presenting hypoglycemic activity, a reported activity since the 1990s by several authors [1, 2, 3]. Another species that has shown scientific importance is the Bauhinia pentandra has been shown antiulcer activity4 and acts on the inhibition of coagulation factor XIla [5, 6]. The species Bauhinia pentandra (Bong.) Vog. ex Steud (Fabaceae) is known in the Northeast of Brazil as "Mororó-de-espinhos" and can be found in the region of the Caatinga and the transition between caatinga forest-savanna. The stem bark can be used popularly as cleanser tonic and in the treatment of diabetes [7].

Among the substances already identified in species of Bauhinia are beta-sitosterol and kaempferol-3, 7-dirhamnoside (kaempferitrin) [8], the latter being responsible for the hypoglycemic properties of $B$. forficate [9].
Pablo Antonio Maia de Farias ${ }^{1,2}$,

Ana Luiza de Aguiar Rocha Martin',

Patrícia Gonçalves Pinheiro1, Modesto Leite Rolim Neto ${ }^{3}$, Tania Maria Sarmento da Silva ${ }^{4}$,

Marta Maria de França Fonteles ${ }^{2}$

1 Faculty of Medicine from Juazeiro do Norte -Estácio FMJ-College of Pharmacy.

2 Federal University of Ceará, UFC -Department of Pharmacy.

3 Federal University of Cariri, UFCA

-Department of Medicine.

4 Federal Rural University of Pernambuco, UFRPE -Department of Molecular Sciences.

Contact information:

Pablo Antonio Maia de Farias.

Tel: (055) (88)3572-7810

Address:Departamento de Farmácia, Faculdade de Medicina Estácio de Juazeiro do Norte (Estácio FMJ).

Av. Tenente Raimundo Rocha, 515

- Cidade Universitária- Juazeiro do Norte

-Ceará- Brazil. CEP 63.040-780

$\equiv$ pablomaia@gmail.com 
Other plants of the same genus have been investigated because they have important therapeutic properties. Recently, investigation of root bark of $B$. pentandra (Fabaceae) led to the isolation and characterization of a new cianoglicosídeo has been termed Riachin. Preliminary studies have demonstrated antioxidant activity in tests 2,2-diphenyl-1-picrylhydrazyl (2,2-diphenyl-1-picrylhydrazyl, DPPH) and 2.20-azino-bis (3-ethylbenzthiazoline-6-sulphonic acid) [2,2-azino-bis (ethylbenzo thiazoline--6-sulfonic acid) diammonium salt, $A B D S]$, in addition to displaying chelating activity of metals to ferrous ions (Fe 2+) [10]. However, such studies are very recent and there is still much to be learned about the said cianoglicosídeo.

\section{Method}

This article aims to discuss new strategies for the study and drug development allowing they occur objectively and can reduce the unnecessary and unspecific use of animals in experiments.

The articles referenced in this narrative were identified through the PubMed database from November 2014 to February 2015. His full versions were obtained through the portal of periodicals of CAPES (Coordenação de Aperfeiçoamento Pessoal de Nível Superior) that provides access to texts full available in more than 37,000 periodicals, Brazilian and international publications. The authors were limited to reference texts published in English, Portuguese, Spanish, French or Italian.

As an example, the authors report the initial findings of the activities detected by Riachin, a cianoglicosídeo not cyanogenic obtained from Bauhinia pentandra and isolated in laboratories of the Federal Rural University of Pernambuco.

\section{Results}

\section{Non-cyanogenic cianoglicosídeo}

The cianoglicosídeos are commonly known for their ability to intoxicate, however, some of these may have pharmacological activities such as anti-allergic [11] without risk of toxicity. Drugs with such features correspond to a restricted group, since much of the cianoglicosídeos in nature is cyanotic. This means that they have a nitrile group adjacent to the alpha glycosidic bond, so that these glycosides to hydrolysis by glycosidases, followed by oxidation of the resulting cyanohydrin releases the corresponding aldehyde or ketone and hydrogen cyanide (HCN).

Many vegetables that have cyanogenic compounds have use for animal and human consumption made restrictively and require a lot of care, such as grinding and heating food until the cyanide is almost completely eliminated. Although Riachin corresponds to a cianoglicosídeo the position of the cyano group is not adjacent to the glycosidic bond in the molecule, which causes hydrolysis does not result in the release of cyanide, reducing their toxic capacity. In this context, Riachin fits into a restricted group cianoglicosídeos not cyanogenic such as Simmodisin [12] and Laphoriside isolated from Lophira alata, a common plant in Africa [13]. More recently cianoglicosídeos called ehretiosides were isolated, which showed activity antagonist to histamine [14].

The basic structure of this class has been set [15] and characterized later as a non-cyanogenic cianoglicosídeo [16], but under specific conditions may release a small amount of cyanide [17].

Non-cyanogenic cianoglicosídeos correspond to a group of substances poorly studied, however, appear to exhibit different activities in various systems, since the immune and nervous systems, as well as antimicrobial activity.

Currently, it was started a investigation about the pharmacological properties of Riachin, for 
there were not enough reports to direct further research. Typically using techniques of screening pharmacological for this purpose. The major problem of such thrust can be in the excessive use of animals for research random yet been reported properties.

\section{Animal use in pharmacological studies}

The use of animals in pharmacological studies is a common practice worldwide. In 2010, the United States used approximately 1.37 million animals in experiments. Note that these figures do not include rats, mice, birds and fish, as these animals are not covered by the "Animal Welfare Act," signed in 1966 by the US government and aims to establish minimum acceptable standards for the care and treatment with animals. Therefore, most of the procedures were performed in mice and rats (96\%). Other commonly used animals include those of guinea pigs (19\%), rabbits (18\%) and hamsters (13\%) [18].

In 2011, the United Kingdom has used more than three million animals which included mainly mice (71\%), fish (15\%), rats (7\%) and birds (4\%) [18].

In Brazil, Law 11.794, published in 2008, known as Arouca law, regulates research and teaching through the use of animals19. One must understand that the publication of the rule of law does not preclude the research activity with animals, but only imposes limits necessary for the use of these is carried out rationally so as to avoid suffering the same.

To meet the demands raised by this scenario computational studies have emerged as an important tool for scientists and environmentalists have met their objectives even partially. Currently, an array of features is available to enhance the search and the study of new molecules through statistical and mathematical predictions based on the characteristics of the chemical structures.

\section{New technologies for new drug discovery}

Since the 1970s a number of advances in chemistry and molecular and cellular biology attracted the attention of researchers in the pharmaceutical industry. So that between the late 1970s and early 1980s the techniques of studies involving recombinant DNA became focus of work of some companies, for example, Genentech and Amgen. The use of these new technologies has gained strength with the creation of Epogen (a stimulant erythropoietin) and recombinant insulin [20].

With the discovery of techniques involving monoclonal antibodies, research around this knowledge has become a true fever at early 2000's, so that about $25 \%$ of all new developing drugs were monoclonal antibodies [20].

With the knowledge provided by the Genome Project and consequently on proteins, it was perceived that the real targets for various diseases could be studied more precisely, from that developed the techniques of genetic knock-out studies [20]. This new scenario led knowledge to a new context, that the molecular pathways are responsible for different diseases or have an important causal role. Thus, there is a new paradigm in the search for new treatments interfering up more objectively, at the molecular level in the pathological mechanisms.

With the advent of X-ray crystallography, molecular design went to another level with a considerable wealth of details and data that made it possible in 1987, featuring an HIV protease using computer models. Later, in 1997, such advent led to the development of a protease inhibitor called Nelfinavir. Despite this highly successful, many others have not resulted in the same outcome, therefore, it was perceived that the biological properties of a molecule dependent on other factors.

The computational tools did not arise randomly, these were only possible after the emergence of biotechnology databases that resulted in mathema- 
tical models to analyze the relationships between the structures and the pharmacological effects reported in several articles.

This process would not be possible without the development of computer and the internet itself, at least not in the proportions that can be seen today. You can start this methodological approach in the 1970s with the emergence of the first database consists of 12 structures that have gone through evaluation crystallographic. This first step allowed biotechnological developments which resulted in 1982 with the creation of the first insulin produced by recombinant DNA technique licensed by Genentech and produced by the pharmaceutical company Eli Lilly [21]. This resulted in the creation of the first Knockout mouse by researchers Martin Evans, Oliver Smithies and Mario Capecchi [22].

In the following years, a number of new knowledge was consolidated, resulting in the development of drugs that employ this new knowledge as the basis for the research, among these new drugs have emerged Rituxan, Viracept, the Vitravene and Lipitor, the first synthetic statin. In the early 2000 s more than 2,500 pharmaceutical companies have developed drugs with the application of new technologies [20].

\section{Computer studies}

The new drug research is developed by a large set of essential science for the discovery of new molecules and co-participation of this science is indispensable for achieving the main goal, to become a real drug. However, this trajectory is complex and requires large investments, resulting often in a molecule unfeasible due to the lack of relevant biological activity, the toxicity or the difficulty of achieving the pharmacological targets in a living by pharmacokinetic complications.

The steps leading up to the pre-clinical and clinical studies are crucial to obtain much information about the substance to be tested, which can often lead to impossibility of its use previously.
Therefore, current computer models can provide more information in a timely manner so that the researcher can direct their research on new molecules. Such studies may provide resources from the identification of the most likely pharmacological properties [23] of a molecule to the prediction of its possible adverse events [24].

It is in this context that since the early 2000s, with the knowledge from the Human Genome Project, several publications related to the creation of computer models that simulate the activity, interaction and pharmacokinetics of molecules are emerging.

Computational studies of drugs are known as in silico studies, expression that seems to have been first used in 1989 in the workshop "Cellular Automata: Theory and Applications" in the United States, but gained a larger dimension with the Genome Project. Although the most suitable expression, maybe it was in silicio, to keep momentum of the expressions in vivo, in vitro, ex vivo, appearing in Latin, the expression in silico had already spread so that it remained. It is noteworthy that not everything that is done on the computer is a study in silico, this expression is valid only for studies that simulate natural processes [25].

The in silico studies can be performed starting with the molecular target which is sought molecules in databases that may interfere positively or negatively in said target, or a small molecule upon which it is desired to know their properties.

The in silico study offers some advantages, such as reducing the number of molecules to be tested by means of databases, greater speed in the experiments and in achieving results and reducing the use of animals. However, factors such as the flexibility of the protein molecule to the molecular conformation and promiscuity hamper more accurate predictions [26].

\section{Five rule and the viability of drug}

A drug after being prepared as a medicine can be administered in various ways, either via a parenteral, 
Figure 1: Drug route to their biological viability (Adapted from Van de Waterbeemd, 2003) [27].

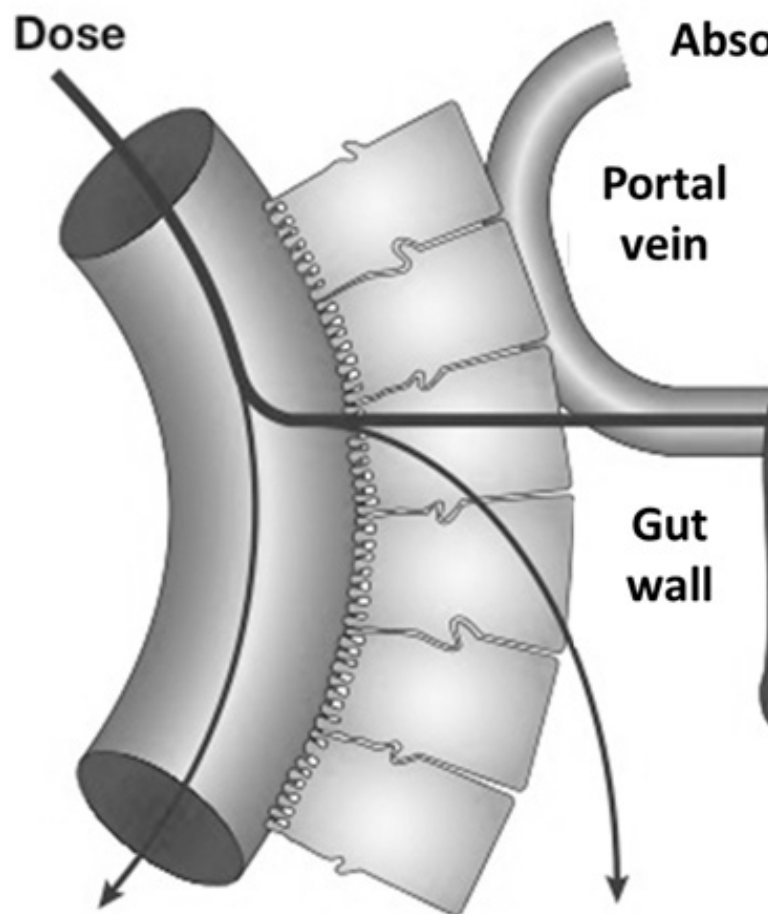

Faeces
Metabolism

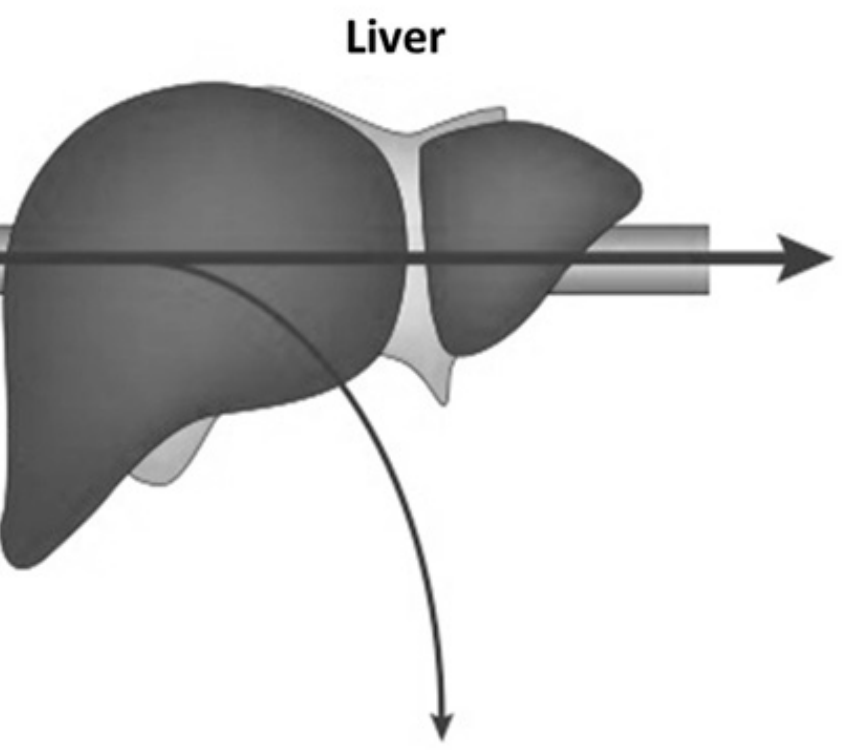

Metabolism dermal, rectal, among others. However, the most comfortable way for the patient is oral, therefore, the drug should be able to cross a series of obstacles to reach the site of action [27] (Figure 1).

Remember that a drug must meet some important criteria to ensure its effectiveness, as good proportion of solubility oil/water to diffuse through the membrane and be well distributed; have adequate size so you can permeate the body to the site of action and have limited affinity to proteins, and other, otherwise the molecule in question may lose its function and not become a drug.

Observing various physicochemical characteristics and some biological factors Lipinski (2004)28, from the year 1997, studied the influence of these factors on the pharmacokinetic properties of drugs and came to the conclusion that some properties are essential for a molecule (druglikeness) has a higher probability of becoming a drug:

a. Molecular weight is less than or equal to 500 $\mathrm{Da}$; b. Number of hydrogen bond acceptor groups is less than or equal to 10 (expressed as the sum of $\mathrm{N}$ and $\mathrm{O}$ atoms);

c. Number of hydrogen bond donor groups is less than or equal to 5 (expressed as the sum of $\mathrm{OH}$ and $\mathrm{NH}$ in the molecule);

d. cLog $P$ is less than or equal to 5 .

The fact that each parameter is defined by a value which, coincidentally, is a multiple of five took this set of factors to be called "Rule of Five". This study was based on the evaluation of a set of 2,245 new chemical species (NCS) that were collected from the World Drug Index (WDI) [29].

of course, over time, other researchers discuss and improved this rule found that other factors may influence the pharmacological properties of a molecule, such as, for example, polar surface area (PSA) of less than $140 \AA 2$, which can best mean oral bioavailability for the drug [30].

The physico-chemical properties will lead directly into the molecular pharmacokinetics, a candidate 
for drug need to have good pharmacokinetic characteristics to increase your chances of becoming a medicine. However, it is estimated that approximately $50 \%$ of the drug candidates fail because of problems with the absorption, distribution, metabolism, excretion or toxicity31. The evaluation of all the related parameters is defined as ADMET originating in the acronym of the steps of pharmacokinetic evaluation.

\section{ADMET studies}

Until the 1980s the pharmaceutical industry devoted their pharmacokinetic investigations using animals. In these studies were determined the nature of the absorption, distribution, metabolism and excretion (ADME) of drugs. Such studies led long time, which postponed the onset of pre-clinical and clinical studies. Another problem was the failure rate representing wasted time and money.

The early ADME studies report to the 1960s with the work of some authors. Until the 1970s, these models were typically based on in vivo studies. From the 1980s, ADME evaluation techniques in vitro became incorporated. In vitro studies, for example, Caco-2, pharmacokinetic characteristics studied in an experimental model of epithelial cells from a colorectal carcinoma [32] composed a literature data set containing information on absorption, drug interactions (drug \pm drug interactions - DDI), drug carriers and efflux pumps (P-glycoprotein - P-gp, Multidrug Resistance Protein - MRP), intrinsic clearance and brain penetration, which already believed-that could be used to predict the in vivo situation in humans [33].

In the early 2000s it was known that deficiencies in ADME characteristics corresponded the main cause of friction during drug development and in the same period was in sight the hope that one day the chemistry might be able to design the ideal chemistry for creating of new drugs [31].

The process of building ADME and toxicology studies known as ADMET corresponds to an arduous trajectory of work, starting from the selection of diseases, target identification, the identification of binding agents, optimization of these agents, selection of candidates and preclinical evaluation thereof. The next step is to identify the disease to be the target of research and components that are part of the biochemical pathways (proteins, genes, receptors) play an important role in the disease. Once these targets have been identified, one can synthesize a variety of substances that may interact with them [34].

The next step is to optimize the substance with main objective of applying concepts of structureactivity relationship, SAR, and structure-metabolism relationship, SMR, to improve these links. The next steps are the tests on animals and then in humans [34].

\section{Structure-activity relationship}

The evaluation methods of Quantitative structureactivity, QSAR, have shown efficient and relevant results having the pharmaceutical industry as the primary user of these strategies. The results are the fruit of linear regression analysis, using neural networks and other [35].

The QSAR studies are based on the principle that the biological activity of a molecule is related to its chemical structure. This enables prediction of the pharmacodynamic and pharmacokinetic activities based on theoretical models [36]. Studies of structure-activity relationship, SAR, qualitative study qualitative relationships derived from non-continuous data, while QSAR are derived from continuous data (e.g. data on the toxic potential). In 1863, Cros had noted such relations to publish "Action de l'alcohol amylique sur l'organisme", studying the relationship between the toxicity of primary aliphatic alcohols and their solubility in water [37].

Currently, it is understood that a QSAR study should: I - be associated with a defined endpoint; II - in the form of an unambiguous algorithm is easy to implement; III - the ideal is to have a me- 
chanistic interpretation; IV - be accompanied by a definition of applicability domain; $V$ - be associated with a measure of "goodness-of-fit" (corresponding to internal validation); VI - be evaluated in terms of its predictive power using unused data in the development of the model (which corresponds to the external validation) [38].

According to Oecd (2014) [37] biological activity (either pharmacological or toxicological) of substances is governed by its structural properties and SAR methods use such properties to achieve two objectives: I - determine, as precisely as possible, the variation limits of the chemical structure that is consistent with producing a particular effect (for example, a chemical can cause specific toxic endpoint); II - define the ways that changes in the structure influence the power of the endpoint.

QSAR models are usually based on mathematical relationships, most often statistics that relate to the structural properties and the presence or absence, the potency or activity of interest [37].

\section{Discussion}

\section{Predictions regarding Riachin}

To facilitate the evaluation of the data, the molecular structure of Riachin was presented as being obtained by SMILE PubChem software, available in https://pubchem.ncbi.nlm.nih.gov/search/search. cgi\#, resulting in the representative: $\mathrm{C} 2 \mathrm{C}(\mathrm{C} / \mathrm{O}[\mathrm{H} @$ $\mathrm{H}] 1 \mathrm{C}(\mathrm{C}=\mathrm{CC}(\mathrm{C} 1 \mathrm{O}) \mathrm{O}) \mathrm{N}=\mathrm{CC} \#)$ OC (C (C2O) O) CO) $\mathrm{O}$, with substituents in position 4 described in Figure 2 [10].

The in silico studies were performed by first forming structure shown in Figure 2.

Preliminary studies of Riachin molecule determine the related properties in Table 1.

TPSA: Topological Polar Surface Area; N. atoms: number of atoms; MW: molecular weight; nON: hydrogen bond acceptors; nOHNH: hydrogen bond donos; N. violations: number of violations of rule of
Figure 2: General structural formula of Riachin [10].
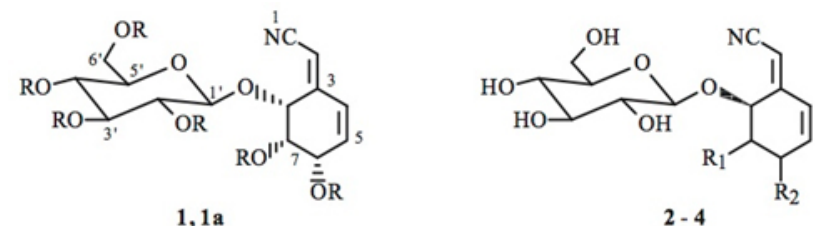

1: $\mathrm{R}=\mathrm{H} ; 1$ a: $\mathrm{R}=\mathrm{Ac} ; 2: \mathrm{R}_{1}=\alpha \mathrm{OH}, \mathrm{R}_{2}=\beta \mathrm{OH}$

3: $\mathrm{R}_{1}=\mathrm{R}_{2}=\alpha \mathrm{OH} ; 4: \mathrm{R}_{1}=\mathrm{R}_{2}=\beta \mathrm{OH}$

Table 1.

\begin{tabular}{|l|c|l|}
\hline \multicolumn{1}{|c|}{ Parameter } & Result & \multicolumn{1}{c}{ Source } \\
\hline CLogP & $-2,74$ & Osiris \\
\hline TPSA & 163,628 & Molinspiration \\
\hline $\mathrm{N}$. atoms & 23 & Molinspiration \\
\hline $\mathrm{MW}$ & 329,305 & Molinspiration \\
\hline $\mathrm{nON}$ & 9 & Molinspiration \\
\hline $\mathrm{nOHNH}$ & 6 & Molinspiration \\
\hline $\mathrm{N}$. violations & 1 & Molinspiration \\
\hline Toxicity (DL50) & Class IV & Protox \\
\hline Druglikeness & $(310 \mathrm{mg} / \mathrm{Kg})$ & Osiris \\
\hline Drug-score & $-8,1$ & Osiris \\
\hline
\end{tabular}

TPSA: Topological Polar Surface Area; N. atoms: number of atoms; MW: molecular weight; nON: hydrogen bond acceptors; nOHNH: hydrogen bond donos; N. violations: number of violations of rule of five. Availability: Osiris (http://www.organic-chemistry.org/prog/peo/); Molinspiration (http://www.molinspiration.com); Protox (http://tox.charite.de/tox/).

five. Availability: Osiris (http://www.organic-chemistry.org/prog/peo/); Molinspiration (http://www.molinspiration.com); Protox (http://tox.charite.de/tox/).

\section{Predictions in silico regarding Riachin}

In the current phase, based on in silico studies techniques were designed experimental models in order to study the pharmacological properties of Riachin objectively, reducing the waste of time and excessive use of laboratory animals. 


\section{Predictions of physical and chemical properties}

The physico-chemical properties were determined through Molinspiration software, available on the website http://www.molinspiration.com. Founded in 1986 as a spin-off from the University of Bratislava, the Molinspiration is a private company focusing on the development and application of modern techniques of chemical informatics, especially in connection with the web. This method is very robust and is able to process almost all organic and organometallic molecules39.

In Molinspiration software it is possible calculate the coefficient octane/water partition (log P), molecular volume, molecular weight, number of rotatable bonds, the number of hydrogen bond acceptor groups and donor [29] and molecular surface area (TPSA) [40]. Furthermore, it is possible to predict the score of bioactivity for different pharmacological targets [41, 42].

As already mentioned, although the drawings of drugs based on the structure is effective, many drugs do not even come to clinical studies for problems in the pharmacokinetics and toxicity.

The drug-likness is a qualitative property of chemical products which was awarded in a vote of a committee of experts which is widely used in the early stages of drug discovery [43]. There are many approaches on how to evaluate the drug-likeness of a molecule, such as topological descriptors, fingerprints CDM key structure or other properties such as cLogP and molecular weights. The approach used in this study is based on a list of about 5,300 fragments of different substructure with drug-likeness scores associated. The list of fragments was created from 3,300 marketed substances and commercially available chemicals to give a complete list of all available fragments [44].

In addition to the drug-Likness, will also be determined the drug score, with scores obtained by combining the results of drug-likeness, CLogP, molecular weight and risk of toxicity in an affordable value that can be used to judge the global potential of the compound to qualify as a future drug.

The drug-likeness is calculated through the fragments of point values that are present in the molecule under investigation, and the calculations made through the online software Osiris, available at [45] http://www.organic- chemistry.org/prog/peo/.

The value of the drug score is calculated by multiplying the contributions of the individual properties of the molecule with the first phase of the calculations (Figure 3):

Figure 3: Equation for the score calculation drug used by Osiris software [45].

$$
d s=\pi\left(\frac{1}{2}+\frac{1}{2} s_{i}\right) \times \pi t_{i}
$$

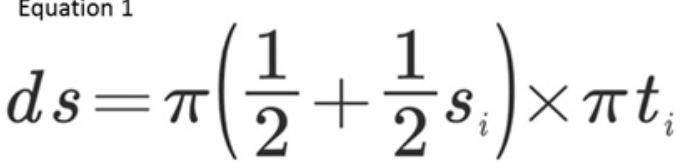

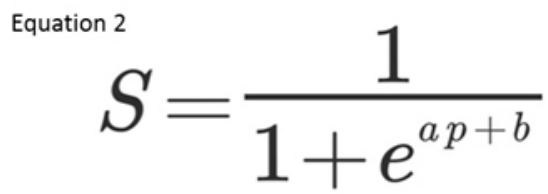

Where "ds" is the drug score; "Si" are contributions calculated directly from cLogP, LogS, molecular weight and drug-likeness (pi) through the second equation describing a spline curve. The parameters "a" and "b" are (1, -5); (1, 5); $(0.012,-6)$ and (1, $0)$ to CLogP, records, molecular weight and druglikeness, respectively, and "ti" are the contributions of the types of risks taken IV toxicity. The values of "ti" are 1.0, 0.8 and 0.6 for no risk, medium risk and high risk, respectively [45].

\section{Conclusion}

Drug research came in the early twenty-first century in a new dimension being must satisfy important environmental and economic needs. The initial findings of Riachin exemplifies the use of simple initial strategies for objective search pharmacological activities of isolated substances. It is possible that in 
the near future, such procedures may be required prior to any kind of pharmacologic screening. Such a strategy should minimize considerably the unnecessary use of laboratory animals.

Pharmacological studies for investigation of Riachin activity were started and all the tests should be directed by in silico predictions. The in silico studies hold great promise for the detection of pharmacological targets and new molecules. So every month the number of publications seems to increase considerably, as the number of available tools.

\section{References}

1. Russo EM, Reichelt AA, De-Sá JR, Furlanetto RP, Moisés RC, Kasamatsu TS et al. Clinical trial of Myrcia uniflora and Bauhinia forficata leaf extracts in normal and diabetic patients. Braz J Med Biol Res, 1990, v. 23, n. 1, p. 11-20.

2. Silva FR, Szpoganicz B, Pizzolatti MG, Willrich MA, de Sousa E. Acute effect of Bauhinia forficata on serum glucose levels in normal and alloxan-induced diabetic rats. J Ethnopharmacol, 2002 v. 83 , n. 1-2, p. 33-7.

3. Lino CdE S, Diógenes JP, Pereira BA, Faria RA, Andrade Neto M, Alves RS et al. Antidiabetic activity of Bauhinia forficata extracts in alloxan-diabetic rats. Biol Pharm Bull, 2004, v. 27, n. 1, p. $125-$ 7.

4. Akhtar AH, Ahmad KU. Anti-ulcerogenic evaluation of the methanolic extracts of some indigenous medicinal plants of Pakistan in aspirin-ulcerated rats. J Ethnopharmacol, 1995, v. 46, n. 1, p. 1-6.

5. Sampaio CA, Oliva ML, Tanaka AS, Sampaio MU. Proteinase inhibitors in Brazilian Leguminosae. Mem Inst Oswaldo Cruz, 1991, v. 86, n. 2, p. 207-9.

6. Sampaio CA, Motta G, Sampaio MU, Oliva ML, Araújo MS, Stella RC et al. Action of plant proteinase inhibitors on enzymes of the kallikrein kinin system. Agents Actions Suppl, 1992, v. 36, p. 191-9.

7. Agra MDF, Silva KN, Basílio IJLD, Freitas PF, Barbosa-Filho JM. Survey of medicinal plants used in the region Northeast of Brazil. Rev. bras. farmacogn., 2008, v. 18, n. 3, p. 472-508.

8. Da Silva KL, Biavatti MW, Leite SN, Yunes RA, Delle Monache F, Cechinel Filho V. Phytochemical and pharmacognositc investigation of Bauhinia forficata Link (Leguminosae). Z Naturforsch C, 2000, v. 55, n. 5-6, p. 478-80.

9. Jorge $A P$, Horst $H$, de Souza $E$, Pizzolatti MG, Silva FR. Insulinomimetic effects of kaempferitrin on glycaemia and on 14C-glucose uptake in rat soleus muscle. Chem Biol Interact, 2004 , v. 149 , n. 2-3, p. 89-96.
10. Silva TMS, Lins ACS, Sarmento-Filha MJ, Ramos CS, Agra MF, Camara CA. Riachin, a new cyanoglucoside from Bauhinia pentandra and its antioxidant activity. Chem. Nat. Compd., 2013, v. 49, n. 4, p. 685-690.

11. Yoshikawa M, Shimada $H$, Shimoda $H$, Matsuda $H$, Yahamara J, Murakami N. Rhodiocyanosides A and B, new antiallergic cyanoglycosides from Chinese natural medicine "si lie hong jing tian", the underground part of Rhodiola quadrifida (Pall.) Fisch. et Mey. Chem Pharm Bull (Tokyo), 1995, v. 43, n. 7, p. 1245-7.

12. Elliger CA, Waiss AC, Lundin RE. Simmondsin, an unusual 2-cyanomethylenecyclohexyl glucoside from Simmondsia californica. J. Chem. Soc., Perkin Trans. 1,1973, p. 2209-2212.

13. Murakami A, Ohigashi H, Tanaka S, Hirota M, Irie R, Takeda N et al. Bitter cyanoglucosides from Lophira alata. Phytochemistry, 1993, v. 32, n. 6, p. 1461-1466.

14. Simpol LR, Otsuka H, Ohtani K, Kasai R, Yamasaki K. Nitrile glucosides and rosmarinic acid, the histamine inhibitor from Ehretia philippinensis. Phytochemistry, 1994, v. 36, n. 1, p. 9195.

15. Sosa A, Winternitz F, Wylde R, Pavia AA. Structure of a cyanoglucoside of Lithospermum purpureo-caeruleum. Phytochemistry, 1977, v. 16, n. 6, p.707-709.

16. Nahrstedt A, Wray V. Structural revision of a putative cyanogenic glucoside from llex aquifolium. Phytochemistry, 1990, v. 29, n. 12, p. 3934-3936.

17. Lechtenberg M, Nahrstedt A. "Cyanogenic glycosides". In: Ikan R (ed.) Naturally Occurring Glycosides. Chichester: John Wiley, 1999.

18. Badyal DK, Desai C. Animal use in pharmacology education and research: the changing scenario. Indian J Pharmacol, 2014, v. 46, n. 3, p. 257-65.

19. BRASIL. Law No 11.794. From October 8, 2008. Regulates the item VII of $\S 1$ of art. 225 of the Federal Constitution, establishing procedures for the scientific use of animals; repealing Act in 6638, to May 8, 1979; and other measures. Brasília-DF:DOU. Law No 11.794: 1-2p. 2008.

20. Gershell LJ, Atkins JH. A brief history of novel drug discovery technologies. Nat Rev Drug Discov, 2003, v. 2, n. 4, p. 321-7.

21. Gottinger $H$, Umali C, Floether F. Strategic alliances in biotechnology and pharmaceuticals. New York: Nova Science, 2010. ISBN 978-1-60876-997-1. Available in: < http://strateccon.net/assets/strategic_alliances_biopharm.pdf - page=45 >. Acesso em: 02/22/2015.

22. The mouse genome. Nature, 2002, v. 420, n. 6915, p. 510-510.

23. Ekins S, Mestres J, Testa B. In silico pharmacology for drug discovery: methods for virtual ligand screening and profiling. $\mathrm{Br}$ J Pharmacol, 2007b, v. 152, n. 1, p. 9-20.

24. LaBute MX, Zhang $X$, Lenderman J, Bennion BJ, Wong SE, Lightstone FC. Adverse drug reaction prediction using scores produced by large-scale drug-protein target docking on highperformance computing machines. PLoS One, 2014, v. 9, n. 9, p. e106298. 
25. WIKIPÉDIA, C. D. In silico. Flórida, 27 março 2013 22h22min UTC 2013. Available in: < http://pt.wikipedia.org/wiki/In_silico $>$. Access in: 15/09/2014.

26. Ekins S, Mestres J, Testa B. In silico pharmacology for drug discovery: applications to targets and beyond. Br J Pharmacol, 2007 a, v. 152 , n. 1, p. 21-3.

27. Van de Waterbeemd $H$, Gifford E. ADMET in silico modelling: towards prediction paradise? Nat Rev Drug Discov, 2003, v. 2, n. 3, p. 192-204.

28. Lipinski CA. Lead- and drug-like compounds: the rule-of-five revolution. Drug Discov Today Technol, 2004, v. 1, n. 4, p. 33741.

29. Lipinski CA, Lombardo F, Dominy BW, Feeney PJ. Experimental and computational approaches to estimate solubility and permeability in drug discovery and development settings. Adv Drug Deliv Rev, 2001, v. 46, n. 1-3, p. 3-26.

30. Clark DE, Pickett SD. Computational methods for the prediction of 'drug-likeness'. Drug Discov Today, 2000, v. 5, n. 2, p. 49-58.

31. Hodgson, J. ADMET--turning chemicals into drugs. Nat Biotechnol, 2001, v. 19, n. 8, p. 722-6.

32. Artursson P, Palm K, Luthman K. Caco-2 monolayers in experimental and theoretical predictions of drug transport. Adv Drug Deliv Rev, 2001, v. 46, n. 1-3, p. 27-43.

33. Ekins S, Waller CL, Swaan PW, Cruciani G, Wrighton SA, Wikel $\mathrm{JH}$. Progress in predicting human ADME parameters in silico. J Pharmacol Toxicol Methods, 2000, v. 44, n. 1, p. 251-72.

34. Gombar VK, Silver IS, Zhao Z. Role of ADME characteristics in drug discovery and their in silico evaluation: in silico screening of chemicals for their metabolic stability. Curr Top Med Chem, 2003, v. 3, n. 11, p. 1205-25.

35. Dastmalchi S.; Hamzeh-Mivehroud M.; Asadpour-Zeynali K. Comparison of Different 2D and 3D-QSAR Methods on Activity Prediction of Histamine H3 Receptor Antagonists. Iran. J. Pharm. Res., v. 11, n. 1, p. 97-108, 2012.

36. Esposito EX, Hopfinger AJ, Madura JD. Methods for applying the quantitative structure-activity relationship paradigm. Methods Mol Biol, 2004, v. 275, p. 131-214.

37. OECD. Introduction to (Quantitative) Structure Activity Relationships. Paris, France, 2014. Available in: < http://www.oecd.org/chemicalsafety/risk-assessment/ introductiontoquantitativestructureactivityrelationships.htm>. access in: 18/09/2014.

38. Veras LDS, Masamoto A, Funatsu K, Takahata Y. 2D and 3D QSAR studies of the receptor binding affinity of progestins. J. Braz. Chem. Soc., 2010, v.21, p.872-881.

39. Sheikh J, Hatzade K, Bader A, Shaheen U, Sander T, Ben Hadda T. Computational evaluation and experimental verification of antibacterial and antioxidant activity of 7-hydroxy-3- pyrazolyl4H-chromen-4-ones and their O-glucosides: identification of pharmacophore sites. Medicinal Chemistry Research, 2014, v. 23, n. 1, p. 243-251.
40. Ertl P, Rohde B, Selzer P. Fast calculation of molecular polar surface area as a sum of fragment-based contributions and its application to the prediction of drug transport properties. J. Med. Chem., 2000, v. 43, n. 20, p. 3714-7.

41. Ertl P. Molecular structure input on the web. J Cheminform, 2010, v. 2, n. 1, p. 1.

42. CHEMINFORMATICS, M. Molinspiration. Nova Ulica, 2014. Available in: <http://www.molinspiration.com>

43. Ursu O, Rayan A, Goldblum A, Oprea TI. Understanding druglikeness. WIREs Comput Mol Sci, 2011, v. 1, n. 5, p. 760-781.

44. Osiris. Available in: <http://www.organic-chemistry.org/prog/ peo/>. Access in: 22/09/2014

45. Jarrahpour A, Fathi J, Mimouni M, Ben Hadda T, Sheikh J, Chohan Z et al. Petra, Osiris and Molinspiration (POM) together as a successful support in drug design: antibacterial activity and biopharmaceutical characterization of some azo Schiff bases. Medicinal Chemistry Research, 2012, v. 21, n. 8, p. 1984-1990.

\section{Comment on this article:}

\section{(f) in $8+\boldsymbol{S}$ P}

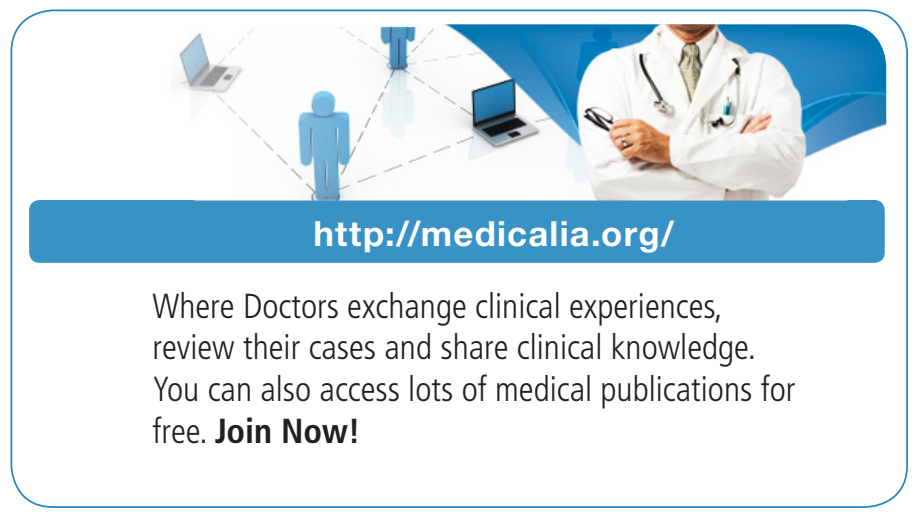

Publish with iMedPub

http://www.imed.pub

International Archives of Medicine is an open access journal publishing articles encompassing all aspects of medical science and clinical practice. IAM is considered a megajournal with independent sections on all areas of medicine. IAM is a really international journal with authors and board members from all around the world. The journal is widely indexed and classified Q1 in category Medicine. 